\title{
PROSESI IMPLEMENTASI PESTA ADAT MARIMPA SALO DI DESA BUA KECAMATAN TELLULIMPOE KABUPATEN SINJAI
}

\author{
Sukma Indah, Abdul Rahman A. Sakka
}

Universitas Negeri Makassar, Sulawesi Selatan, Indonesia.

Email: sukmaindah0325@gmail.com, abdul.rahman8304@unm.ac.id

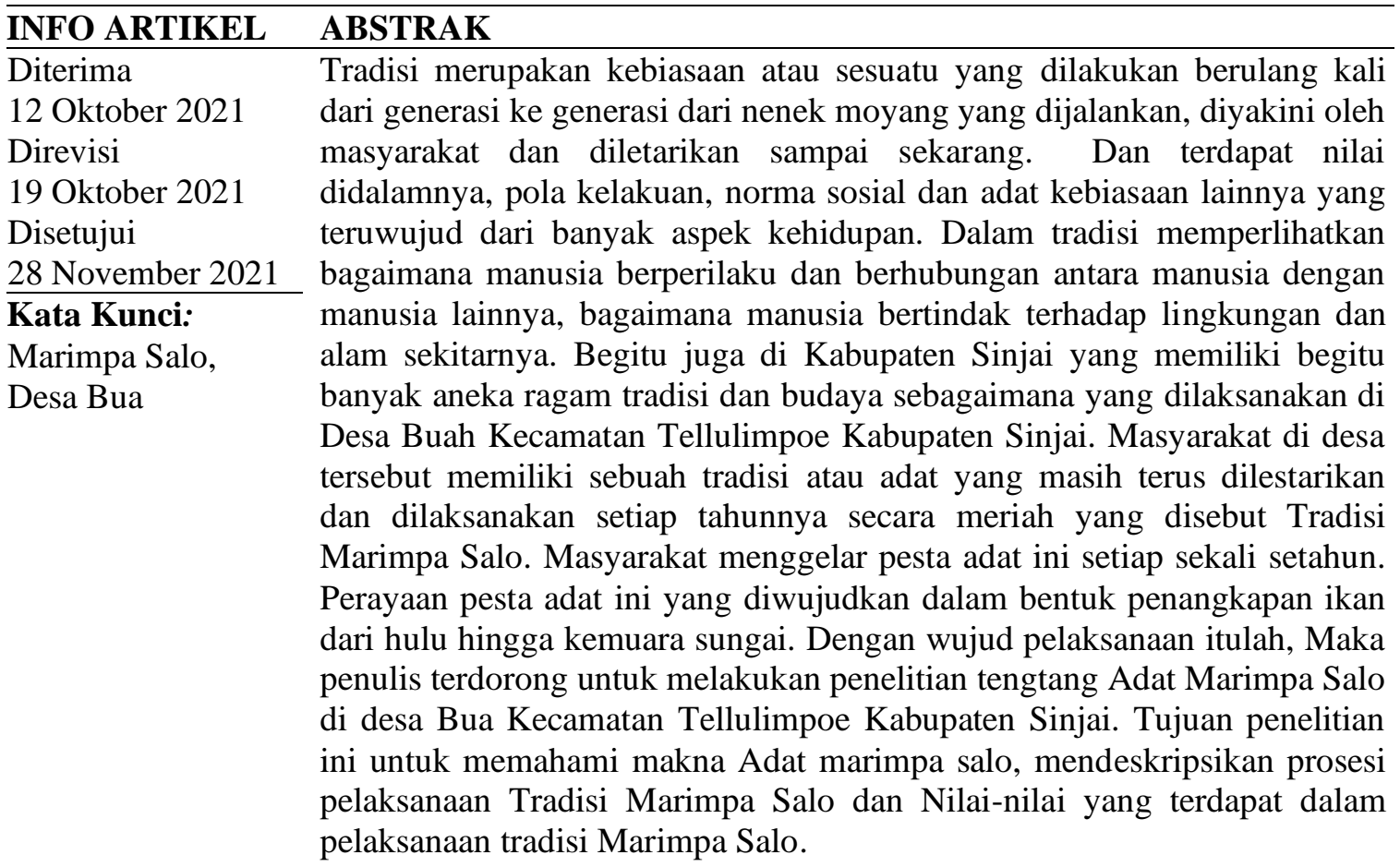

\section{ABSTRACT}

Tradition is a habit or something that is done repeatedly from generation to generation from ancestors that are run, believed by the community and preserved until now. And there are values in it, patterns of behavior, social norms and other customary customs that are affected by many aspects of life. Tradition shows how humans behave and relate between humans and other humans, how humans act towards the environment and the surrounding nature. Likewise in Sinjai Regency which has so many diverse traditions and cultures as carried out in The Fruit Village of Tellulimpoe District of Sinjai Regency. The people in the village have a tradition or custom that is still preserved and carried out every year in a festive manner called the Marimpa Salo Tradition. People hold this traditional party once a year. This traditional feast celebration is manifested in the form of fishing from upstream to the mouth of the river. With the implementation of that, the author was encouraged to conduct research on marimpa salo customs in bua village tellulimpoe district of Sinjai regency. The purpose of this study is to understand the meaning of marimpa salo Keywords: $\quad$ custom, describing the procession of the implementation of the Marimpa Marimpa Salo, Salo Tradition and the values contained in the implementation of the

$\begin{array}{ll}\text { How to cite: } & \text { Indah, S., \& Abdul Rahman A. Sakka (2021). Prosesi Implementasi Pesta Adat Marimpa Salo Di Desa } \\ & \text { Bua Kecamatan Tellulimpoe Kabupaten Sinjai, Action Research Literate, 5(2). } \\ \text { E-ISSN: } & \text { 2808-6988 } \\ \text { Published by: } & \text { Ridwan Institute }\end{array}$




\section{Pendahuluan}

Wilayah Indonesia yang begitu luas dengan memiliki beragam ras dan suku sehingga melahirkan beraneka ragam kebudayaan kemudiaan dilestaraikan dari masa lalu sampai sekarang secara turun temurun (Sakirin, 2018). Dari kebudayaan manusia dapat berkarya menjadikan mereka sebagai manusia yang beradab, manusia yang berbudaya dan terhormat didalam kehidupan bermasyarakat.

Manusialah yang membuat sendiri kebudayaan karena budaya bukan sesuatu yang diturunkan secara biologis, akan tetapi kebudayaan didapatkan dengan cara mencari tahu atau dipelajari dan kebudayaan bisa juga didapatkan dengan menjadi anggota masyarakat karena semua tingkah laku dan tindakan manusia yang dilakukan berulang kali juga disebut kebudayaan (Abdullah, 2017). Budaya dapat diuraikan sebagai seperangkat nilai, keyakinan, aturan dan adat istiadat yang bisa mewajibkan setiap individu kepada kesadaran bersama di dalam lingkup masyarakat umum. Unsur-unsur budaya masih dapat dipertahankan jika masih memiliki manfaat dan peranan dalam kehidupan masyarakat. Sebaliknya unsur kebudayaan akan punah jika tidak lagi memiliki manfaat di kehidupan masyarakat (Saidah, 2017).

Meskipun beberapa masyarakat disebuah daerah sudah tidak dapat lagi mempertahankan dan melestarikan budaya dan adat leluhur mereka yang sudah diwariskan secara turun temurun oleh nenek moyang mereka karena tidak semua manusia menganggap positif budaya dan adat akan tetapi ada juga manusia yang menganggap bahwa budaya tidak sejalan dengan perkembangan zaman. Sewaktu-waktu bisa saja budaya akan terlengserkan dengan perkembangan zaman pola berpikir masyarakat lambat laun akan banyak berubah dengan arus globalisasi yang sebelumnya tradisi atau adat dipandang sebagai sesuatu yang sangat bernilai kemudian berganti menjadi sesuatu yang tidak ada nilainnya (Jamaludin, 2015).

Marimpa Salo merupakan pesta adat yang rutin dilaksanakan setiap tahun sebagai rasa syukur atas keberhasilan panen ikan para nelayan yang mereka wujudkan dalam bentuk menghalau ikan dari hulu sampai ke muara sungai. Banyak warga yang ikut serta menyaksikan pesta adat ini karena tidak hanya dengan cara menghalau ikan tapi juga dirangkaikan dengan pertunjukan lainnya seperti mangadakan perlombaan domino, menghias perahu nelayan, catur dan lomba menangkap bebek serta beberapa perlombaan lainnya. Uniknya pesta adat ini dilakukan setiap tahun tapi didesa yang berbeda Desa buah kecamatan tellulimpoe dan desa takkalala kecamatan sinjai timur dan diselang-seling waktu pelaksanaannya (KURNIA, 2016).

Masyarakat yang bermukim dipesisir merupakan sebuah kelompok manusia yang mempunyai kebiasaan hidup dan budi pekerti serta ciri tertentu yang berdiam diwilayah perbatasan antara lautan dan daratan. Masyarakat yang bermukim dibagian pesisir ini memenuhi kebutuhan hidupnya dari hasil sumber laut seperti menangkap ikan. Mayarakat pesisir juga memiliki budaya dan tradisi yang berbeda beda seperti di Desa Bua yang merupakan salah satu desa yang berada di Kecamatan Tellulimpoe Kabupaten Sinjai. Desa ini juga merupakan desa yang tertua di Kecamatan Tellulimpoe. Desa buah juga terletak di bagian perbukitan dan pesisir. Dan jaraknya dengan ibu kota kabupaten sinjai cukup jauh yaitu sekitar $13 \mathrm{Km}$. Selain itu, desa Bua ini juga merupakan salah satu desa yang masih melestarikan kebudayaan dan adat istiadatnya. Salah satu adat yang masih dilaksanakan dan dilestarikan sampai 
sekarang yaitu tradisi Marimpa Salo. Yang merupakan sebuah adat yang diwariskan secara turun-temurun dilaksanakan setiap tahun. Adat ini diyakini oleh masyarakat sebagai adat dari bentuk kesyukuran masyarakat terhadap hasil panen yang melimpah dari sungai (A Kurnia, 2014).

Dalam setiap daerah masing-masing masyarakat memiliki budaya dan tradisi yang memiliki sejarah dan makna tersendiri dengan budaya dan tradisi tersebut manusia dapat berkarya, sehingga menjadikan mereka sebagai manusia yang berbudaya, beradab, terhormat dan kehidupan manusia menjadi seimbang serta memiliki gerak yang normatif menuju tingkat kehidupan yang lebih tinggi. Disebuah daerah yang memiliki budaya dan tradisi yang bervariasi, unik dan mempunyai nilai nilai yang positif di dalam kehidupan masyarakat (Arwansyah et al., 2017).

Budaya dapat diartikan sebagai seperangkat nilai nilai, cara-cara hidup yang dimiliki masyarakat dan berkembang didalam kehidupan bermasyarakat (Zafi, 2018). Didalam kehidupan bermasyarakat mereka masih melestarikan kebudayaannya. Meskipun saat sekarang ini zaman sudah sangat modern dengan adanya teknologi yang masuk ke daerahnya tapi mereka tetap mempertahankan berbagai tradisi dan berbagai upacara-upacara lainnya. Tapi tidak bisa juga dipungkiri bahwa ada dari beberapa mereka yang sudah tidak memperdulikan lagi tradisi semacam ini.

\section{Metode Penelitian}

Penelitian ini memakai metode penelitian kualitatif deskriptif (Suyitno, 2018). Yang dimana penelitian kualitatif deskriptif adalah dapat melahirkan dan mengelola data yang memiliki sifat deskriptif seperti salinan wawancara dan observasi. Metode kualitatif ini digunakan untuk mengerti mengenai fenomena Nampak dan dalam keadaan yang alamiah. Bukan didalam keadaan yang sedang terkendali. Dengan jenis metode penelitian kualitatif deskriptif ini dianggap sangat tepat digunakan karena peneliti terjung langsung ke lapangan.

Sebagaimana permasalahan yang menjadi titik fokus penelitian ini yaitu mengenai tentang implementasi pesisir adat marimpa salo yang berada di desa Bua kecamatan tellulimpoe, sehingga peneliti menggunakan kualitatif untuk mendeskripsikan data yang telah peneliti dapatkan sebagai hasil dari sebuah penelitian. Dengan metode yang digunakan ini maka peneliti bisa mengumpulkan data secara utuh dan mendalam sehingga hasil penelitian sesuai dengan keadaan yang terjadi di dapangan. Peneliti juga mengumpulkan data dari tulisan-tulisan yang terkait dengan marimpa salo setelah data terkumpul kemudian disatukan agar supaya memudahkan peneliti untuk melakukan proses penulisan (Wijaya, 2018).

Dalam penelitian kualitatif peneliti merupakan alat pengumpul data utama dan merupakan salah satu unsur yang sangat penting di dalam pengumpulan data. Alat (Instrumen) yang utama digunakan adalah manusia karena hanya manusia yang dapat melakukan interaksi langsung dengan responden serta mampu melihat secara langsung fakta-fakta yang ada di lapangan. Oleh sebab itulah peneliti juga sangat berperan dalam kehidupan lapangan atau objek yang diamati. Selain itu peneliti juga menggunakan alat (instrument) lainnya seperti alat tulis dan handphone sebagai alat pendukung.

\section{Hasil dan Pembahasan}

Di Desa Bua, Masyarakat masih melaksanakan pesta adat yaitu Marimpa Salo. Marimpa salo mempunyai makna sebagai bentuk rasa syukur para nelayan atas keberhasilaan tangkapan ikan (Ma'paenre bale). Masyarakat merealisasikan bentuk syukurnya dengan cara menghalau ikan-ikan dari hulu hingga ke muara sungai yang 
dilakukan setiap tahunnya, hanya saja setiap tahunnya pelaksanaanya dilaksanakan di dua tempat secara bergantian yaitu didesa Bua kecamatan Tellulimpoe dan didesa Sanjai dikecamatan Sinjai Timur Kabupaten Sinjai.

Marimpa Salo (Menangkap Ikan) yang dilaksanakan dalam rangka merayakan hasil dari panen laut. Adat ini dirayakan oleh masyarakat yang berdiam di bagian pesisir pantai Desa Sanjai, Sinjai Timur dan pantai Desa Bua, Sinjai Tellelimpoe yang setiap tahunnya dirayakan dengan menghalau ikan dari hulu sampai ke muara sungai sembari para warga menghalau ikan tradisi ini juga dibarengi dengan penampilan tarian appadekko yang menunjukkan upacara masyarakat para nelayan, menyantap hasil dari tangkapan ikan, selain dari itu juga dilakukan adu ketangkasan pencak silat. Sebagai bentuk kebahagian masyarakat pesisir yang menikmati hasil tangkapan para nelayan selama setahun telah berikhtiar mencari rezeki di lautan lepas.

Saat matahari di ufuk timur telah terbit maka itu tandanya warga harus bersiap siap menggelar acara. Dipesisir sungai Bua yang menjadi tempat digelarnya pesta adat dan ratusan warga ikut serta memeriahkan acara adat ini dengan cara menghalau ikan dari hulu hingga ke muara. Kemudian gendang dimainkan sebagai tanda bahwa semua warga didesa tersebut dipanggil untuk berkumpul dan mempersiapkan diri untuk mengikuti pelaksanaan pesta adat Marimpa Salo. Kemudian beberapa nelayan memulai menghias perah-perahunya dengan memakai daun kelapa muda yang nantinya perahuperahu tersebut akan dipakai untuk menghalau ikan-ikan dari hulu hingga ke muara.

1. Prosesi Perayaan Marimpa Salo

Prosesi ialah langkah-langkah yang dilakukan didalam sebuah perayaan atau pelaksanaan upacara atau tradisi. Dalam setiap perayaan yang dilaksanakan memiliki prosesi tersendiri.
Sebelum tradisi Marimpa Salo dilaksanakan segenap masyarakat terlebih dahulu melakukan duduk bersama (Tudang Sipulung) untuk bermusyawarah untuk membahas tentang persiapan pelaksanaan tradisi Marimpa Salo dan juga membahas tentang pembagaian tugas untuk masyarakat yang turut berpartisipasi dalam pelaksanaan yang terdiri dari : Gella (Kepala Kampung), Arung (Kepala desa), Pabelle (Menyiapkan perlengkapan bagian laut), Panitia Acara, Ponggawa Lopi (Mengendalikan Perahu), Sawi (Awak Perahu), Paggenrang (Komponen Pemusik), Sanro (Dukun), Paddareheng atau Paddawa-dawa(orang-orang yang menyediakan makanan yang akan disantap bersamaan saat pelaksanaan Marimpa salo). Setelah semua komponen-komponen telah terbentuk maka selanjutnya adalah mempersiapkan sarana dan prasarana yang digunakan saat pelaksanaan tradisi marimpa salo. Seperti: Perahu (Lopi), Belle (Tempat Ikan), Rompong (Alat bantu penangkapan ikan), Lanra (Jaring), Tenda, Bambu (untuk membuat Walasuji), Daun Kelapa yang masih muda.

Pada hari dimana acara Marimpa Salo dilaksanakan dimulai dengan suara tabuhan gendang tradisional di muara sungai Desa Bua yang merupakan isyarat akan dimulainya acara marimpo salo dan para warga desa sudah dipanggil dan kemudian berkumpul menyiapkan diri mengikuti acara tradisi Marimpa Salo. Sembari tabuhan gendang dimainkan para nelayan sudah memulai memberi hiasan pada perahunya dengan memakai daun kelapa. Dimana para perahu yang telah diberi hiasan tersebut nantinya akan dipakai untuk menghalaui ikan dari hulu hingga ke muara sungai Desa Bua. Dan juga diiringi dengan berbagai tarian yang biasa dipertunjukkan pada saat acara berlangsung seperti: Tari Maddongi, Tari Mappadekko, Tari Pangguna Salo, Tari 
Massulo Uwae agar supaya masyarakat berlomba-lomba dan bersemangat mengikuti tradisi Marimpa Salo.

$$
\text { Para Pabelle (Menyiapkan }
$$

perlengkapan bagian laut) mulai menurunkan puluhan perahu, kemudian para warga diantar oleh Ponggawa Lopi dan Awak Perahu menuju ke hulu sungai. Setelah itu perahu-perahu diatur sesuai lebarnya sungai serta pemasangan jarring dan rompong. Ponggawa Lopi (Mengendalikan Perahu) mulai menaiki dan membawa perahu kemudian menarik tali pengingat jarring dan rompong hingga ke muara sungai dan acara inti pun dimulai, masyarakat meyakini sebelum acara Tradisi Marimpa Salo di mulai dilakukan terlebih dahulu tabuhan gendang tradisional guna mengingat ikanikan agar tidak pergi jauh. Kemudian dua perahu saling menarik jarring menuju muara sungai, setelah itu Belle (Penangkap Ikan-ikan) diposisikan di bagian muara sungai sesudah itu para Parrimpa (Penghalau) berada disisi Belle saat ikan sudah dipastikan masuk ke dalam perangkap, maka Belle itupun di tutup.

Setelah ikan-ikan itu berhasil masuk ke dalam perangkap, para warga berbondong-bondong turun menuju Belle untuk mengambil ikan dengan menggunakan Jala dan diberikan untuk dimasak oleh para paddareheng atau pandawa-dawa yang akan mengolah ikan tersebut. Kemudian ikan-ikan yang berhasil ditangkap setelah dikelola seperti dimasak atau dibakar yang akan disajikan bagi masyarakat dan tamu-tamu yang datang, yang disantap bersama dengan berbagai makanan lainnya yang sudah disiapkan oleh paddareheng seperti, burasa, onde-onde, sokko, gogoso dan berbagai macam makanan lainnya.

Perayaan Tradisi Marimpa Salo bukan hanya dilakukan dan dimeriahkan oleh warga Desa Bua dan sekitarnya saja akan tetapi juga turut dilaksanakan dan dimerihkan oleh segenap Pemerintah Kabupaten Sinjai.

$$
\text { Kepada Desa Bua juga }
$$

mengungkapkan pelaksanaan prosesi Tradisi Marimpa salo ini tidak terlepas dari seluruh pihak masyarakat yang turut bekerjasama, dimana tradisi Marimpa Salo ini merupakan budaya kearifan local pada masyarakat peseisir kabupaten sinjai yang harus tetap dilestarikan.

2. Nilai Nilai yang terkandung didalam Implementasi tradisi Marimpa Salo

a. Nilai Solidaritas

Tradisi ini telah meningkatkan solidaritas bagi Masyarakat antara Desa Bua dan Desa Sanjai, walaupun berbeda Kecamatan akan tetapi dua desa ini sangat antusias terhadap perayaan tradisi Marimpa Salo.

b. Nilai Sosial

Tradisi ini memiliki nilai social yang tinggi, karena kerjasama dan kepudulian masyarakat terhadap tradisi ini. Dan juga menjadi salah tempat bersilaturahmi antara Masyarakat desa lainnya serta sanad keluarga yang jauh karna saat perayaan Tradisi Marimpa Salo banyak warga yang dari merantau pulang kekampung halaman agar mereka bisa ikut merayakan tradisi ini.

c. Nilai Ekonomi

Dalam tradisi Marimpa Salo merupakan kegiatan yang masyarakat lakukan secara gotong royong yang melibatkan banyak warga Desa Bua dan desa sekitarnya. Keadaan seperti ini pasti menguntungkan bagi para pedagang kaki lima karena mereka dapat menjual dagangangnya diacara tersebut.

d. Gotong Royong

Dari Tradisi Marimpa Salo ini juga mewujudkan gotong royong antar sesama masyarakat karena mereka sama-sama melakukan kegiatan 
pembersihan pesisir di Desa Bua setelah melaksanakan Adat Marimpa salo. Masyarakat juga melakukan kerja sama yang baik pada saat proses pelaksanaan tradisi Marimpa Salo agar supaya acara tersebut terlaksana dengan baik. Nilai kebersamaan juga sangat diperhatikan dan dijunjung tinggi oleh masyarakat Desa Bua..

\section{Kesimpulan}

Dari Tradisi Marimpa Salo ini dapat disimpulkan bahwa Marimpa Salo (Menghalau Ikan) dilaksanakan dalam rangka merayakan hasil dari panen laut. Adat ini dirayakan oleh masyarakat yang pesisir pantai Desa Sanjai, Sinjai Timur dan pantai Desa Bua, Sinjai Tellelimpoe yang setiap tahunnya dirayakan dengan menghalau ikan dari hulu sampai ke muara sungai. Sebelum tradisi Marimpa Salo dilaksanakan segenap masyarakat terlebih dahulu melakukan duduk bersama (Tudang Sipulung) untuk bermusyawarah untuk membahas tentang persiapan pelaksanaan tradisi Marimpa Salo dan juga membahas tentang pembagaian tugas untuk masyarakat yang turut berpartisipasi dalam pelaksanaan yang terdiri dari: Gella (Kepala Kampung), Arung (Kepala desa), Pabelle (Menyiapkan perlengkapan bagian laut), Panitia Acara, Ponggawa Lopi (Mengendalikan Perahu), Sawi (Awak Perahu), Paggenrang (Komponen Pemusik), Sanro (Dukun), Paddareheng atau Paddawa-dawa(orangorang yang menyediakan makanan yang akan disantap bersamaan saat pelaksanaan Marimpa salo). Setelah semua komponenkomponen telah terbentuk maka selanjutnya adalah mempersiapkan sarana dan prasarana yang digunakan saat pelaksanaan tradisi marimpa salo. Seperti: Perahu (Lopi), Belle (Tempat Ikan), Rompong (Alat bantu penangkapan ikan), Lanra (Jaring), Tenda, Bambu (untuk membuat Walasuji), Daun Kelapa yang masih mudah.
Dalam pelaksanaan Tradisi Marimpa Salo juga ditampilkan beberapa tarian seperti Tari Maddongi, Tari Mappadekko, Tari Pangguna Salo, Tari Massulo Uwae agar supaya masyarakat berlomba-lomba dan bersemangat mengikuti tradisi Marimpa Salo. Adapun makna yang terkandung didalam Tradisi Marimpa Salo yaitu sebagai bentuk kesyukuran masyarakat atas keberhasilan setelah melaksanakan panen..

\section{Bibliografi}

A Kurnia, A. K. (2014). Pelaksanaan Tradisi Marimpa Salo di Desa Sanjai Kecamatan Sinjai Timur Kabupaten Sinjai. Universitas Negeri Mkassar.Google Scholar

Abdullah, O. S. (2017). Ekologi manusia dan pembangunan berkelanjutan. Gramedia Pustaka Utama. .Google Scholar

Arwansyah, Y. B., Suwandi, S., \& Widodo, S. T. (2017). Revitalisasi peran budaya lokal dalam materi pembelajaran bahasa Indonesia bagi penutur asing (BIPA). Proceedings Education And Language International Conference, 1(1). .Google Scholar

Jamaludin, A. N. (2015). Sosiologi perkotaan: memahami masyarakat kota dan problematikanya. Pustaka Setia. .Google Scholar

Kurnia, A. (2016). Pelaksanaan Tradisi Marimpa Salo Pada Masyarakat Desa Sanjai Kecamatan Sinjai Timur Kabupaten Sinjai. Jurnal Tomalebbi, 2(2), 19-23. .Google Scholar

Saidah, M. (2017). Unsur-unsur Budaya Islam dalam Tradisi Pernikahan Masyarakat Jawa Timur di Desa Bangun Jaya Kecamatan Tomoni Kabupaten Luwu Timur. Universitas Islam Negeri Alauddin Makassar. .Google Scholar

Sakirin, A. (2018). Mengenal Pluralisme Disintegratif Menuju Pluralisme 
Integratif Masyarakat Beda Agama di Kelurahan Karang, Kecamatan Slogohimo, Kabupaten Wonogiri. Ibriez: Jurnal Kependidikan Dasar Islam Berbasis Sains, 3(2), 179-198. .Google Scholar

Suyitno. (2018). Penelitian kualitatif (A. Tanzeh (ed.); 1st ed.). Akademia Pustaka. .Google Scholar ilmu pendidikan teologi. Sekolah Tinggi Theologia Jaffray. .Google Scholar

Zafi, A. A. (2018). Transformasi budaya melalui lembaga pendidikan (pembudayaan dalam pembentukan karakter). Al Ghazali, 1(1), 1-16. .Google Scholar

Wijaya, H. (2018). Analisis data kualitatif

\section{Copyright holder :}

Sukma Indah, Abdul Rahman A. Sakka (2021).

First publication right :

Action Research Literate

This article is licensed under:

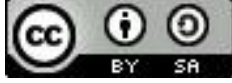

